\title{
Daring to Dare-Theoretical Experiment for Pedagogical Practices and Body-Brain-Embedded Subject
}

\author{
Edyta Just \\ Gender Studies, Department of Thematic Studies, Linköping University, Linköping, Sweden \\ Email: edyta.just@liu.se
}

Received 14 December 2015; accepted 21 February 2016; published 26 February 2016

Copyright (C) 2016 by author and Scientific Research Publishing Inc.

This work is licensed under the Creative Commons Attribution International License (CC BY). http://creativecommons.org/licenses/by/4.0/

(c) (i) Open Access

\section{Abstract}

This article discusses and experiments with a psychological constructionist account of the brain basis of emotion-the conceptual act model (Lindquist et al., 2012; Barrett et al., 2014) and the Deleuzian and Guattarian $(1987 ; 2009)$ philosophical accounts of affect, concept and stratum. Why those two? The conceptual act model theorizes process of meaning making of external and internal sensations including experience of emotions. Deleuze and Guattari, with their accounts, reflect on various patterns of making meaning comprising those that lead to self-/criticism and creativity. Since it is crucial to think about teaching practices that support students in daring to challenge, problematize and generate new meaning of experienced sensations, theories that address meaning making processes are of particular relevance. This article shows that those theories alone and once exposed to an experiment may possibly inspire pedagogical undertakings that aim to create self-/critically-creative abilities among students, but also add to the ways of conceptualizing subject, body, mind and brain.

\section{Keywords}

Conceptual Act Model, Emotions, Affect, Concept and Stratum, Meaning Making, Pedagogy, Self-/Critically-Creative Abilities, Subject, Body, Mind and Brain

\section{Introduction}

This article states that it is of the vital importance that students are able to be self-/critical and creative resisting existing habits and opinions (Waaldijk \& Just, 2010). Furthermore, it dares to contend that in order to become self-/critical and creative, students should be able to challenge, play with and problematize the meaning of expe- 
rienced external and internal sensations including experience of emotions, and to generate and conjure a new one. Those educational goals unquestionably require and call for new pedagogical practices. In this article, the author undertakes an effort to search for theories that can inspire novel pedagogical undertakings. Given the author's interest in theories of subject, body, mind and brain, an inspiration is looked for among those. Apart from bringing the existing subject, body, mind and brain theories to the fore, the author also attempts to experiment with them. Those discussions and experiments are approached as utterly vital mostly due to the fact that their results may not only encourage innovative pedagogical practices, but also contribute to the ways of thinking subject, thinking body, thinking mind, thinking brain. Since it is the author's conviction that the most daring and resourceful epistemologies seem to grow from the application of the interdisciplinary approaches, this article brings together various disciplines and especially philosophy, neuroscience and pedagogy.

This text discusses and experiments with a psychological constructionist account of the brain basis of emotionthe conceptual act model (Lindquist et al., 2012; Barrett et al., 2014) ${ }^{1}$ and the Deleuzian and Guattarian (1987; 2009) philosophical accounts of affect, concept and stratum. Why those two? The conceptual act model theorizes process of meaning making of external and internal sensations including experience of emotions. Deleuze and Guattari, with their accounts, reflect on various patterns of making meaning comprising those that lead to self-/ criticism and creativity. Since it is crucial to think about teaching practices that support students in daring to challenge, problematize and generate new meaning of experienced sensations, theories that address meaning making processes are of particular relevance. Those theories alone and once exposed to an experiment may possibly inspire novel pedagogical undertakings that aim to create self-/critically-creative abilities among students, but also add to the ways of conceptualizing subject, body, mind and brain. Importantly, it is not argued that the chosen theories convey an uncontested "truth" or that other theories addressing the similar issues are in any sense problematic or inapplicable. It is rather that the author has developed a particular scientific affinity with the conceptual act model and the Deleuzian/Guattarian concepts that stand behind the choice of theoretical framework for this article.

To render the discussion as comprehensible as possible, the article begins by introducing and discussing the conceptual act model and the Deleuzian and Guattarian philosophical concepts respectively simultaneously highlighting their contribution to the ways of thinking subject, body, mind and brain. Then, it describes a theoretical experiment, where those theories become combined together, and presents the implications such experiment might have for the manners of conceptualizing subject, body, mind and brain. Finally, it brings to the fore the implications those theories separately and together may possibly have for pedagogical practices that mind students' self-/critically-creative capabilities.

\section{Situated Conceptualization-Meaning Making Process}

“[T]he brain's architecture can be thought of as a situated conceptualization generator producing the individual brain states that correspond to each individual mental state” (Barrett et al., 2014: p. 447). What is then situated conceptualization? Situated conceptualization is said to be process of making meaning of bodily sensations (interoceptive sensory information) and/or sensations from the external world (exteroceptive sensory information) "using representations of prior experience” (Lindquist et al., 2012: p. 125; Barrett et al., 2014). Situated conceptualization "links perceptions of sensory input from the world with input from the body to create a meaningful psychological moment” and as such "internal sensory cues or their associated affective feelings are automatically and effortlessly made meaningful (i.e., experienced as related to or caused by an event or object, usually in the external surroundings)” (Lindquist et al., 2012: pp. 124, 125). Internal sensory cues are referred to as core affect and described as "the mental representation of bodily changes that are sometimes (but not always) experienced as feelings of hedonic pleasure and displeasure [core affective feelings] with some degree of arousal” and is [core affect] "realized, in part, by visceral control systems (...)," and "accompanied by somatovisceral, kinesthetic, proprioceptive, and neurochemical fluctuations that take place within the core of the body and are represented in the brain” (Lindquist et al., 2012: p. 124).

How is it possible that the brain makes meaning of internal and external input? According to the researchers

\footnotetext{
${ }^{1}$ For more on the discussed psychological constructionist account of the brain basis of emotion-the conceptual act model, please consult the following publications: Barrett, L. F. (2006), Solving the emotion paradox: categorization and the experience of emotion; Barrett, L. F. (2009), The Future of Psychology: Connecting Mind to Brain; Barrett, L. F. (2012). Emotions are real; Barsalou, L. W. (2009), Simulation, situated conceptualization, and prediction; Lindquist, K., A. \& Barrett, L. F. (2012), A functional architecture of the human brain: Insights from Emotion; Russell, J. A. (2003), Core affect and the psychological construction of emotion.
} 
the brain is able of storing information associated with certain category that later can be used for process of meaning making related to sensorial input. To render sensorial input meaningful means to determine what the sensory input "is, why it is, and what to do with it” (Barrett et al., 2014: p. 451). Stored knowledge can fuse with “impinging sensory input” and has the ability of "re-enacting or simulating a situation that is not present” (Barrett et al, 2014: p. 451). The first occurs due to the fact that "knowledge is stored and represented in the same format (...) as the sensations” (Barrett et al., 2014: p. 451). The second happens because knowledge is "distributed throughout the brain's modal systems for perception and action in the form of simulators that reenact sensory, action, affect, and other elements of situations captured through experience” (Barrett et al., 2014: p. 451). Every concept "emerges from different multimodal systems in the brain (...) [and] particular modal areas of the brain store information about the category” (Barrett et al., 2014: p. 452). Conceptual knowledge for a given category [e.g., a given object] develops for properties, relations, rules, other objects, setting, actions, words, events or internal states related to that category [i.e., a given object] (Barrett et al., 2014: p. 452). For sensorial input to be processed the brain uses the conceptual knowledge "associated with relevant concepts, to create a novel situated conceptualization, integrating current sensory input and retrieved (modal) conceptual knowledge” and so "the brain produces a conceptual state using multimodal information about entire situations" (Barrett et al., 2014:p. 452). To summarize, process of conceptualization/meaning making stands for linking internal and external sensations with conceptual knowledge; determining what and why a given input (external and internal) is and for creating novel conceptualization that may consist of the past and present external and internal sensations, actions, etc. Thus, to conceptualize/make meaning of is, repeating briefly, to link external and internal sensations with existing knowledge; to determine what and why a given input is and to create novel conceptualization that may contain the past and present sensations, actions, etc. The preceding description allows claiming that the past experience and accumulated conceptual knowledge play significant role in meaning making process. Importantly, conceptual knowledge is able to add novel features to (e.g., conceptual knowledge of certain category may extend a given input) and modify sensorial input (Barrett et al., 2014: p. 448). Yet, a given experience can also inform and modify conceptual knowledge. This enables realization that the past experience (i.e., conceptual knowledge) might be altered and transformed. Importantly, process of meaning making not only serves to determine what and why the sensory input is, but also may entail certain internal states and actions. Since conceptual knowledge for a given category [e.g., object] emerges from different multimodal systems in the brain and encompasses properties, rules, other objects, actions, events, internal states, etc., then e.g., a given external input such as a particular object can mobilize associated with it internal states, actions, etc. Therefore, indeed, it is possible that "what [one has] experienced in the past is very likely what [one] will experience in the present, because stored representations of the past help to constitute the present” (Barrett et al., 2014: p. 450). This again emphasizes the import of the past experience in making sense of the present, but also highlights the logic behind the brain's architecture and connectivity. Moreover, it points out to the embodied and embedded "nature" of meaning making process and problematizes the dualism of cognition and affectivity; thinking, feeling and acting.

Situated conceptualizations occur ceaselessly with regard to external and internal sensations (Barrett et al., 2014). Lindquist et al. emphasize that "[a]t any point in time, the brain is processing information from the body (core affect), information from outside the body (exteroceptive sensory information), and representations of prior experiences (conceptualizations)” (2012: p. 126). Importantly, during process of conceptualization/ meaning making of sensations another process takes place. This process is coined as executive attention. Executive attention is an operation that selects the elements of the information coming from the body, outside of the body and memory in order to create a meaning of what is experienced at a particular moment. To be more precise, executive attention is "the process by which some representations are selectively enhanced and others are suppressed"; it "foregrounds certain core affective feelings and exteroceptive sensory sensations in a moment, and guides which situated conceptualizations are brought to bear to make meaning of those sensations in the given context” (Lindquist at al., 2012: p. 125). Importantly, executive attention can operate in a volitional and non-volitional manner (Lindquist et al., 2012: p. 125). This suggestion is quite appealing as on the one hand, it indicates that process of conceptualization/meaning making is automatic yet, on the other hand, it can be volitionally monitored and altered.

Considerably, process of conceptualization is said to be "represented as a distributed brain state (...) or even a series of brain state transitions across time” (Barrett et al., 2014: p. 455). This is an important statement as it in- 
dicates that "mental causation is not mechanistic per se, but probabilistic" (Barrett et al., 2014: p. 455). This shows that it cannot be easily predicted how process of meaning making will proceed/develop. It depends on conceptual knowledge, executive attention and internal and external sensations how-what is experienced-will become conceptualized. This highlights again the import of one's experience, embodiment and embeddedness (past and present) in process of meaning making.

\section{Emotions as Situated Conceptualizations}

Emotions stand for situated conceptualizations (Lindquist et al., 2012; Barrett et al., 2014). They are "psychological events that emerge out of more basic psychological operations that are not specific to emotion” and that they "emerge when people make meaning out of sensory input from the body [core affect] and from the world [exteroceptive sensory information], using knowledge of prior experiences [conceptualizations]" (Lindquist et al., 2012: p. 123). It is important to add here that "category knowledge about emotions does not cause emotions per se-it constitutes emotions by adding epistemologically novel functions to sensory input and action” (Barrett et al., 2014: p. 455). Notably, it is assumed that "at their core, emotional experience (...) [always] contain[s] a representation of the somatovisceral state [core affect] of the body” (Lindquist et al., 2012: p. 176). The experienced (in one's body) core affect or its associated core affective feelings can be conceptualized as "a physical symptom (...) a simple feeling (...) or an instance of a discrete emotion category (e.g., anger vs. fear)” (Lindquist et al., 2012: p. 124). It is due to process of conceptualization that is of linking internal and/or external sensory input with a priori accumulated knowledge, that one makes sense of what one experiences: a symptom, a feeling or an emotion. This basically indicates that "only some bodily changes are experienced as emotion" (Lindquist et al., 2012: p. 124). This conclusion makes possible a suggestion that indeed an individual life-experience, geo-political location and cultural context apparently play a very significant role in transposing (or not) one's core affect into an emotional episode. It is indeed stressed that "emotion concepts will differ cross-culturally" and that "[e]ven the same emotion categories can contain different content across cultures" (Lindquist et al., 2012: pp. 184-185). However, simultaneously it is suggested that ““[m]inimal 'universality’ (...) might exist because many cultures were subject to similar selection pressures (...) and hence developed similar emotion concepts” (Lindquist et al., 2012: p. 184). In this sense, it is possible to argue that emotions such as fear, anger, disgust, sadness or happiness are not necessarily experienced in the same way by everybody what may indicate that the experience of a given emotional state should not be conceptualized as universal.

Since process of conceptualization/meaning making is accompanied by executive attention and since emotions are defined as situated conceptualizations, executive attention participates in the emergence of experience of emotions. As executive attention can operate in both automatic and volitional manners consequently the experience of emotions might be also automatic or volitional.

Process of conceptualization stands for a distributed brain state. As such an experience of emotions also stands for a distributed brain state, "a dynamic functional network that is generated on the fly during an emotional experience or perception" or "networks that only combine in a given context to produce a given type of mental state” (Lindquist et al., 2012: pp. 141, 180). This dynamic functional network is “constructed from assemblies of neurons that perform sensory, conceptual, attentional and action functions” and changes over time (Barrett et al., 2014: pp. 448, 455). This way, emotion can be understood "not [as] a process but instead represents a category of phenomena-a collection of instances of probabilistic situated conceptualizations” (Barrett et al., 2014: p. 455). As such two claims can be made. First, it can be argued that it might not be easily predicted, anticipated or solved whether the experienced core affect/core affective feelings will be categorized as an instance or a given category of emotion or not. Second, it can be contended that brain regions are "not specific to any emotion category (or even to emotion per se)" and emotions are not "supported by anatomically given, inherited [hard-wired] networks” (Lindquist et al., 2012: pp. 126, 141).

The experience of emotions similarly to other situated conceptualizations does depend on conceptual knowledge, executive attention and internal and external sensations. As such the past experience, the past and present forms of embodiment and embededdness are crucial for the emergence and construction of emotions.

\section{The Deleuzian/Guattarian Philosophical Accounts of Affect, Concept and Stratum}

Indisputably, Deleuze and Guattari $(1987 ; 2009)$ strive to promote manners of meaning making which lead to/ 
stand for self-/criticism and creativity. Manners that oppose the well-known track of habits, customs, opinions and common sense; manners that stand for pure creation and experiment and manners that stand for new meaning and sense which nevertheless will be far from finished or complete (Semetsky, 2009). What is then necessary to generate/conjure/summon new meaning; self-criticism; creativity? The answer would be concept and affect that is respectively conceptual and sensory becoming. For Deleuze and Guattari subjects can become concept that is undergoing conceptual becoming. In order to undergo conceptual becoming subjects need to become affect that is undergoing sensory becoming (Deleuze \& Guattari, 2009). The sensory becoming, which is also referred to as sensation, indicates the moment of becoming other, of deterritorialization, indetermination, indiscernibility, suspension, hesitation, surprise, wonder, intensity and, in a way, lack of meaning (Deleuze \& Guattari, 2009). The conceptual becoming on the other hand, points to a creation of new meaning and novel sense, but also indicates the desirability of an ongoing and infinite movement engendering forever rejuvenating meaning and sense (Deleuze \& Guattari, 2009). The sensory becoming (affects/sensations) can be comprehended as laying ground for the conceptual becoming (concepts), and together they stand for the desirable manners of meaning making. To secure that conceptual becoming occurs and that it never stops happening (i.e., the meaning is always on the move; never finished and complete), conceptual becoming should be tightly interconnected with sensory becoming.

According to Deleuze and Guattari (2009), encounters automatically bring about sensory and conceptual becoming but there is always a possibility that the hesitation and suspension of affect or novelty of concept will be in/voluntarily covered with well too familiar habits, customs and opinions, in short, striated. Therefore, it is important not to halt creative and experimental becomings from happening once they ensue, but also to volitionally stimulate their occurrence. Sensory and conceptual becomings-daring manners of meaning making-necessarily happen in the brain. For Deleuze and Guattari, brain "appears as a faculty of concepts, that is to say, as the faculty of their creation, at the same time that it sets up the plane of immanence on which concepts are placed, move, change order and relations, are renewed, and never cease being created” (2009: p. 211).

Therefore, a "brain-concept" would indicate an "articulation," "heterogenesis", non-stabile and non-fixed reterritorializations and "state of survey” (Deleuze \& Guattari, 2009: pp. 16, 20); an ability to ceaselessly experience new sense and meaning. Since for Deleuze and Guattari “' [s]ensation is no less brain than the concept’ and since sensation is an "excitation itself, not insofar as it is gradually prolonged and passes into the reaction but insofar as it is preserved or preserves its vibrations (...) contracted vibration” (2009: p. 211) then a "brain-affect" would stand for charged with creative potential deterritorializations and indiscernibility; an ability to become surprised and confused, to not know, to hesitate and to wonder. However, as Deleuze and Guattari (1987) seem to claim sometimes it is actually advisable to stick to the well-known meaning and to have/practice, so to say, striated manners of meaning making. It has been already mentioned that striated manners of making meaning involve customary, habitual and unchangeable meaning. Why might then such manners and such meaning be appropriate? It seems that according to Deleuze and Guattari stratification can be as unfortunate as beneficial (1987: p. 40). Unfortunate, because stratum prevents movement and opposes creativity. Beneficial, because it might help one to endure and sustain the experienced indetermination of affect and novelty of concept. It appears that for Deleuze and Guattari the frequency of indeterminate deterritorialization (affect) and new meaning and sense (concept) should fit one's pace.

\section{Theoretical Experiment}

Before plunging into an experiment, for the matter of clarity, let's briefly recall what is understood by conceptualization i.e., meaning making. Conceptualization links external and/or internal sensations with conceptual knowledge. Conceptual knowledge is stored and represented in the same format as the experienced external and internal sensations, can re-enact or simulate a situation that is not present, emerges from different multimodal systems in the brain and develops for properties, relations, rules, other objects, setting, actions, words, events or internal states related to a given category. Conceptualization determines what the experienced external and internal sensations are, why they are and what to do with them. It may consist of the past and present external and internal sensations, actions, etc. Furthermore, conceptualization; meaning making of internal and external sensations implies/involves certain internal states and/or actions. In this sense, in the conceptual act model thinking, feeling and acting are strongly interconnected.

In an experimental way, the author dares to propose to think about conceptualization as the Deleuzian/Guat- 
tarian sensory/conceptual becoming and stratum. Since mental causation is said to be probabilistic and since sensory becoming indicates indetermination one may feasibly recognize a sympathetic (in between disciplines) affinity between those two theories. Associating conceptualization with sensory becoming strengthens the hypothesis that it cannot be easily predicted how external/internal sensations will get conceptualized. -The unpredictable embodied and embedded subject -Furthermore, since, sensory becoming stands for a lack of meaning, conceptualization can be thought of as potentially turning into, colloquially said a particular surprise or state of wonder of the brain. -The wondering subject- Since any conceptualization can be novel and alter conceptual knowledge, and since, conceptual becoming indicates new meaning/sense then conceptualization can be associated not only with the Deleuzian/Guattarian sensory but also conceptual becoming. Approaching conceptualization as conceptual becoming significantly supports the idea of the brain being able to generate new meaning of given sensations and re-write the existing knowledge. As sensory becoming is said to lay ground for conceptual becoming, it could be speculated that once a given input leads to a confusion of the brain, the latter may facilitate creation of a novel meaning for a given external and/or internal input. -The critical and creative subjectGiven that both conceptualization and becomings might be automatic or volitional, associating conceptualization with becomings allows affirming the brain's ability to be creative with or without conscious participation of volition. -The ambiguously automatic/volitional subject -It seems that with the existing plentitude of the stored knowledge, the creativity of the brain and the unpredictability and novelty of conceptualization do not appear as all that unanticipated. Furthermore, to think about conceptualization as sensory becoming that is "brain-affect" is to approach it as a state where the meaning making of sensations might be temporarily suspended and as such it remains unknown what a given sensation is. What is then engendered is a state of indiscernibility and deterritorialization of the brain. This could not only entail that a given input lacks its corresponding conceptual knowledge but also that a given input remains simultaneously similar and different to the memorized concepts. Moreover, to think about conceptualization as intertwinement of sensory and conceptual becoming is to envision it as a state where new meaning is ceaselessly engendered, but also as a state where the final meaning is postponed and/or perhaps never reached. Therefore, it seems possible to speculate that the brain might be seen as not only being able to produce novel sense, but also not to comprehend a given sensorial input or postpone creating a final meaning of a given sensation ad infinitum. -The beautifully open and potential subject- Importantly, conceptualization is said to be to a large extend conditioned by the experience/existing conceptual knowledge. Sensory and conceptual becomings are said to be accompanied by stratification (i.e., customary/unchangeable meaning). Thus, again, the affinity between those two theories might be credibly noticed. Approaching conceptualization as stratum supports the idea of, as the author would put it, "repetitive” brain and in doing so highlights the difficulties of creating new meaning of given sensations and of challenging and altering the existing conceptual knowledge. -The stubborn subject- Yet, to associate conceptualization with stratum is to consider that, perhaps, sometimes it can be predicted indeed how certain external/internal sensations will become conceptualized. -The embodied and embedded predictable subject- Importantly, for Deleuze and Guattari sensory becoming (indetermination; lack of meaning), conceptual becoming (new meaning) and striated manners of making meaning should complement each other. This particular complementation is crucial as it allows one to remain open to indetermination, novelty and change but at the same time supports one in sustaining occurring encounters. -The enduring subject- Since for Deleuze and Guattari too much of deterritorialization, indetermination and novelty might be unsustainable, could then conceptualization be approached as a necessary intertwinement of sensory and conceptual becoming and stratum? Creatively striated brain?-Daring yet, sustainable subject.

\section{Pedagogy Related Reflections}

To repeat briefly, the conceptual act model, the Deleuzian/Guattarian theories and the attempt to experimentally combine them together apart from contributing to the manners of thinking brain, mind, body and subject are also meant to inspire pedagogical undertakings that aim to create critically-creative abilities among students.

The author would like to begin with a reflection which at first may appear rather disempowering yet, eventually might render otherwise. The conceptual act model considers the possibility of the unpredictability of conceptualization. Approaching conceptualization as sensory becoming strengthens the idea of the brain as prone to states of indetermination. This, consequently, sets limits on predicting the outcomes of the meaning making process - it is not always doable to foresee how external and/or internal sensations will become conceptualized. 
Since, conceptualization entails internal states and actions, it might be rather challenging to presume what internal states and actions will get engendered. Such realization highlights the limits of any educational efforts. Thus, educators should remain aware that the undertaken educational efforts may not result in the expected outcomes. Certainly, this is not to say that efforts should not be made. However, to recognize that what educators want to achieve might not be easily attainable, is to allow sensibly questioning the neo-liberal belief in "yes, we [always] can"-this time in the educational context. Striving for an inspiration for the pedagogical practices that aim to create critically-creative abilities among graduates, the author wants to stress that according to the conceptual act model, conceptualization is very individual and experience/existing conceptual knowledge plays crucial role in meaning making. With conceptualization approached as stratum, the idea of the "repetitive" brain does indeed become stronger. This may show that it is not easy for educators to challenge and alter the existing conceptual framework of students. However, the awareness that the process of making meaning heavily relies on the existing conceptual knowledge may facilitate determination of patterns of conceptualization. Though there is always a probability that certain sensations will become conceptualized in habitual/striated ways, there is also a possibility that meaning making of sensations will entail surprise of the brain (sensory becoming) and/or bring about new meaning (conceptual becoming) of given sensations. Therefore, determining or at least trying to make a cartography of an individual conceptual knowledge and patterns of an individual conceptualizations can facilitate actions directed at initiating novel meaning associated with a given internal and external input. Conceptualization can indeed be novel and may alter conceptual knowledge. To conceptualize internal and/or external input in a new way; to conjure new meaning is to create, so to say, new distribution throughout the brain's modal systems; to create new “combination/configuration” of external and internal sensations (and actions); to create new conceptual knowledge for a given category that encompasses, to repeat briefly, properties, relations, rules, objects, setting, actions, words, events or internal states related to that category. As previously said, in the conceptual act model thinking, feeling and acting are strongly interconnected and their separateness seems to be highly questionable. To create new conceptualization; new meaning is to think, feel and act differently. As the author reads it, the conceptual act model allows and permits such possibility. As for Deleuze and Guattari, they claim that new meaning is probable if only one can experience/undergo/become conceptual becoming. How can then educators evoke conceptual becomings among students? How can they stimulate new conceptualizations? The answer is far from simple yet, let's try to cogitate. It seems that incoming external sensations must be delivered in combinations different from those that students have; different from habitual combinations. It can be suggested that university teachers may try to challenge with their own actions and words e.g., the rules, relations and actions customarily related to a given category. They can also create events that bridge and expose students to e.g., words/objects/rules related to one category with actions related to another. Importantly, they can also try, though it is indisputably a very heavy and demanding task, to monitor conceptualization/meaning making of the internal sensations by addressing and talking about them. Educators simultaneously cannot and can predict (an educator's paradox) what internal states and actions they may evoke, yet, they may hope that the created internal states and actions will follow new and daring paths forming new configurations; new conceptualizations. According to the conceptual act model conceptualization might be automatic or volitional. For Deleuze and Guattari conceptual becoming and striated forms can equally be automatic or volitional. If as educators we desire students' conceptualizations, which are equal to conceptual becomings, to be automatic and volitional (affirming and confirming the creative potential of the embodied and embedded brain) then indeed stimulation of new conceptualizations (by manners suggested above) is indispensable. Though it is only a speculation-it can be assumed that once students commence forming new conceptualizations, the forthcoming encounters with any external and internal sensations will not be automatically and/or volitionally covered with the blanket of stratum. For Deleuze and Guattari constant “movement” of meaning is crucial. Securing the automatic and volitional logic of conceptualizations, equal to conceptual becomings, may simultaneously secure the desired "flow" of meaning. For Deleuze and Guattari sensory becoming facilitates the conceptual one. Importantly, their intertwinement is crucial as it stimulates the necessary fluctuations of meaning. If conceptualization is approached as sensory/conceptual becoming where the first facilitates the latter, then, to repeat briefly, it could be said that for the brain to create a novel meaning for a given external/internal input, it should initially experience a brief state of wonder, confusion and lack of meaning. Definitely, the above statement is simply a suggestion growing out of the theoretical experiment; yet, perhaps, worth trying. Notably, the forthcoming proposition is also a speculation yet, again, speculation, possibly, worth exploring. While aiming to stimulate conceptual becoming among 
students, an educator is challenging e.g., the rules, setting, relations and actions habitually related to a given category. She/he is creating situations and events that expose students to hybrids of concepts-adoring an embedded body-brain; sexual difference theory drives cars_let's build one; affect and writing is my desired leg's property. Yet, she/he could try to do it in such way as to first create a brief chaotic moment; unexpected moment; white noise; lack of meaning-a momentary vortex of possible; of indiscernibility. Let's try: adoring, embedded, body, brain, sexual difference, car, building, affect, writing, desired, leg = Aebbsdcbawdl (i.e., a virtual dance of adoring, embedded, body, brain, sexual difference, car, building, affect, writing, desired, leg). It does not make sense... Oh so this could...--this is what an educator may like to hear and experience. Since the intertwinement of conceptual and sensory becoming is crucial; and since, to recall shortly, conceptualization approached as intertwinement of sensory and conceptual becoming allows seeing conceptualization as a state where new meaning is constantly engendered and the final/the only/the forever fixed meaning is postponed or never reached, then an educator could possibly make an effort to mobilize such intertwinement. The Aebbsdcbawdl (sensory becoming) becomes adoring an embedded body-brain or building cars driven by sexual difference theory or a writing, desirable and affective leg (conceptual becoming) to turn into Bbsdbaaewcdl (sensory becoming) to then jump into an affective body-brain; adoring and writing embedded sexual difference theory; legs, driving and building desirable cars (conceptual becoming). In this sense an educator may hope to activate thinking, feeling and acting that are always on the move, never finished, never taken for granted, and never believed in to be final, the only one or finite in their righteousness and certainty. Interestingly, as the author has previously speculated, to think about conceptualization as sensory becoming, is to envision it as a state where the meaning making of sensations might be temporarily suspended and as such it remains unknown what a given sensorial input is. This statement may put educators on guard mostly because wonder, surprise, suspension and lack of meaning might not be productive if endlessly prolonged. Sensory becoming facilitates conceptual one yet, it would be advisable that conceptual becoming does follow sensory becoming. Apparently, suspension and lack of meaning should turn into trembling territory of new meaning and sense. Conceptualization approached as intertwinement of sensory and conceptual becoming secures the rejuvenating movement of meaning and by doing so also prevents one from the slide into endless deterritorialization and indetermination. Let's then mobilize intertwinements in our classrooms. However, let's stimulate not only intertwinements of sensory and conceptual becoming, but also of sensory and conceptual becoming and stratum. It has previously been mentioned that for Deleuze and Guattari too much of indiscernibility and indetermination (sensory becoming), but also of novelty (conceptual becoming) might be unsustainable. If conceptualization is approached as an indispensable intertwinement of sensory and conceptual becoming and stratum, then how such intertwinement could be stimulated by educators? It seems possible to contend, though again it is only a suggestion in need of further reflection, that for conceptualization to become such an intertwinement an exposure to unknown external input; input that is simultaneously unknown and familiar; input that changes over quick succession of time from unknown to familiar and from familiar to unknown or input that may be associated with e.g., two opposite concepts might be applied. Furthermore, since conceptualization similarly to sensory and conceptual becoming can be volitionally monitored and since new meaning for external and internal sensory input can be volitionally created then indeed volitional actions might be encouraged and stimulated. Volitional actions that allow for a lack of meaning; enable to seek out new meaning of the same external/internal sensations; facilitate an exploration of a novel sense of unknown external/ internal sensations and finally make possible a striated, habitual form of thought to appear so that occurring encounters might be endured.

\section{Conclusion}

As it has been stated at the beginning, it is essential that graduates are able to be self-/critical and creative. Though critical and creative abilities, especially in the learning context, constitute the ground for debates (e.g., Chapman \& O’Neill, 2010; Biggs \& Tang, 2007) in this article they are approached as a particular capacity to challenge, problematize and generate new meaning of experienced external and internal sensations including experience of emotions. Therefore, this text brings to the fore the theories that address meaning making processes and may inspire novel pedagogical undertakings, but also add to the ongoing theorizing of brain, body, mind and subject. To stimulate new pedagogical practices, which aim to generate self-/critically-creative abilities among students, and to contribute to the conceptualizing of brain, body, mind and subject, this article has proceeded experimentally by addressing and engendering encounters between a psychological constructionist 
account of the brain basis of emotion—-the conceptual act model and the philosophical accounts of affect, concept and stratum proposed by Deleuze and Guattari. Those theories alone and once in an experiment highlight the logic behind meaning making processes that allows adding to the further theorizing of brain, body, mind and the human subject with the latter possibly theorized as unpredictable and yet, predictable, embodied, embedded, wondering, critical, creative, automatic and volitional in its thinking, feeling and acting, stubborn, full of potential, daring and yet, enduring and sustainable. The logic behind meaning making processes also allows suggesting that the human subject can conceptualize sensations in unpredictable ways; that individual experience matters once meaning is created; that it might be challenging to alter the existing conceptual frameworks yet, not utterly impossible; that it is probable to stimulate different ways of thinking, feeling and acting; that the elements of surprise and wonder may facilitate creation of a new meaning; that a new meaning can be constantly created; that meaning making can result in a continuous lack of meaning and, finally, that it is crucial to permit habitual ways of thinking for the sake of the sustainability of the subject. It is hoped that those findings can inspire pedagogical practices that aim to motivate critical and creative abilities among students; practices that will recognize their own limitations; practices that will be aware of the intertwinement of thinking, feeling and acting; practices striving to draw the cartographies of the students' conceptual frameworks; practices that will make an effort to surprise and to make students wonder; practices that will allow meaning to tremble and to be on the move, meaning never believed to be final in its righteousness and certainty, but also practices that will guard students' endurability and sustainability. Unquestionably, the author is aware of the vast theoretical planes on which various concepts of meaning making, emotions, cognition, affectivity, thinking, feeling, acting, teaching, learning, brain, mind, body and subject are placed and ceaselessly transformed. The author's embodied and embedded conceptual voice enclosed in this article implicitly respects and explicitly attempts to contribute to the changing contours of the theoretical plateaus and their more than real implications.

\section{References}

Barrett, L. F. (2006). Solving the Emotion Paradox: Categorization and the Experience of Emotion. Personality and Social Psychology Review, 10, 20-46. http://dx.doi.org/10.1207/s15327957pspr1001_2

Barrett, L. F. (2009). The Future of Psychology: Connecting Mind to Brain. Perspectives on Psychological Science, 4, 326339. http://dx.doi.org/10.1111/j.1745-6924.2009.01134.x

Barrett, L. F. (2012). Emotions Are Real. Emotion, 12, 413-429. http://dx.doi.org/10.1037/a0027555

Barrett, L. F., Wilson-Mendenhall, C. D., \& Barsalou, L. W. (2014). A Psychological Construction Account of Emotion Regulation and Dysregulation: The Role of Situated Conceptualizations. In J. J. Gross (Ed.), The Handbook of Emotion Regulation (2nd ed., pp. 447-465). New York: Guilford.

Barsalou, L. W. (2009). Simulation, Situated Conceptualization, and Prediction. Philosophical Transactions of the Royal Society B: Biological Sciences, 364, 1281-1289. http://dx.doi.org/10.1098/rstb.2008.0319

Biggs, J., \& Tang, C. (2007). Teaching for Quality Learning at University. New York: McGraw-Hill Companies, Incorporated.

Chapman, E., \& O’Neill, M. (2010). Defining and Assessing Generic Competences in Australian Universities: Ongoing Challenges. Education Research and Perspectives, 37, 105-123.

Deleuze, G., \& Guattari, F. (1987). A Thousand Plateaus. Capitalism and Schizophrenia. London and New York: Continuum.

Deleuze, G., \& Guattari, F. (2009). What is Philosophy? London and New York: Verso.

Lindquist, K. A., Wager, T. D., Kober, H., Bliss-Moreau, E., \& Barrett, L. F. (2012). The Brain Basis of Emotion: A metaAnalytic Review. Behavioral and Brain Sciences, 35, 121-202. http://dx.doi.org/10.1017/S0140525X11000446

Lindquist, K. A., \& Barrett, L. F. (2012). A Functional Architecture of the Human Brain: Insights from Emotion. Trends in Cognitive Sciences, 16, 533-540. http://dx.doi.org/10.1016/j.tics.2012.09.005

Russell, J. A. (2003). Core Affect and the Psychological Construction of Emotion. Psychological Review, 110, 145-172. http://dx.doi.org/10.1037/0033-295X.110.1.145

Semetsky, I. (2009). Deleuze as a Philosopher of Education: Affective Knowledge/Effective Learning. The European Legacy: Toward New Paradigms, 14, 443-456. http://dx.doi.org/10.1080/10848770902999534

Waaldijk, B., \& Just, E. (Eds.) (2010). Tuning Educational Structures in Europe. Reference Points for the Design and Delivery of Degree Programmes in Gender Studies. Bilbao: Universidad de Deusto. 